\title{
Viscous strengthening followed by slip weakening during frictional melting of chert
}

\author{
Ginta Motohashi ${ }^{1 *} \mathbb{D}$, Kiyokazu Oohashi ${ }^{2}$ and Kohtaro Ujiie ${ }^{1}$
}

\begin{abstract}
Pelagic chert is one of the major lithologies in accretionary complexes. Thus, frictional properties of chert at seismic slip rates are important for understanding of earthquake faulting in subduction zones. Here, we conducted highvelocity friction experiments on chert collected from the Jurassic accretionary complex in central Japan at a slip rate of $1.3 \mathrm{~m} / \mathrm{s}$ and normal stresses of 5-13 MPa under room humidity conditions. The results show that initial slip weakening was followed by slip strengthening and subsequent second slip weakening toward a steady-state shear strength. Slip strengthening resulted from the formation of a silica-rich melt layer at lower melting temperatures than expected, which could be due to the presence of water in the illite-containing chert. The second slip weakening may be occurred due to a decrease in shear strain rate associated with the thickening of the melt layer.
\end{abstract}

Keywords: Frictional melting, Pelagic chert, Viscous strengthening, Silica-rich melt

\section{Introduction}

The frictional properties of pelagic chert are important for understanding faulting processes in subduction zones, because chert constitutes one of the major lithologies in subduction zones. Previous friction experiments on silica-rich rocks (e.g., novaculite) suggested that fault weakening is caused by the thixotropic behavior of silica gel (Goldsby and Tullis 2002; Di Toro et al. 2004: Hayashi and Tsutsumi 2010). The formation of silica gel has also been reported from faults in chert (Kirkpatrick et al. 2013). However, it remains unknown whether silica gel forms at seismic slip rates resulting in coseismic weakening of faults.

The $0.5-2 \mathrm{~mm}$-thick pseudotachylytes (i.e., solidified frictionally generated melts produced during seismic slip) were found from the faults in muscovite-bearing quartzite (Bestmann et al. 2011). Recently, Lee et al. (2017) conducted high-velocity $(1.3 \mathrm{~m} / \mathrm{s})$ friction experiments on quartzite, which showed that quartz can melt at lower temperatures $\left(1350-1500{ }^{\circ} \mathrm{C}\right)$ than expected $\left(1730{ }^{\circ} \mathrm{C}\right)$. However, frictional behavior of silica-rich

\footnotetext{
*Correspondence: ginta_m@geol.tsukuba.ac.jp

${ }^{1}$ Graduate School of Life and Environmental Sciences, University

of Tsukuba, 1-1-1 Tennodai, Tsukuba 305-8572, Japan

Full list of author information is available at the end of the article
}

rocks at seismic slip rates and the underlying physical mechanisms remain poorly understood.

To investigate how frictional melting of silica-rich rocks affects coseismic fault strength, we conducted friction experiments on chert at high slip rates of $1.3 \mathrm{~m} / \mathrm{s}$. After the experiments, the resultant microstructures and chemical composition of the experimental shear zone were examined to reveal the underlying physical processes.

\section{Methods}

The samples for the high-velocity friction experiments were collected from pelagic gray chert mainly composed of microcrystalline quartz and radiolarians with a lesser amount of illite distributed in the Jurassic accretionary complex of the Inuyama area, central Japan (Additional file 1). Chert samples were cored using a motor-powered drill to create cylindrical specimens with a diameter of $25 \mathrm{~mm}$ and height of $20 \mathrm{~mm}$. The end surfaces of the specimens were ground with \#100 SiC powders. The specimens were then dried in an oven at $100{ }^{\circ} \mathrm{C}$ for $24 \mathrm{~h}$. To prevent sample destruction via thermal fracturing (Ohtomo and Shimamoto 1994), the specimens near the contact area were surrounded by iron wires. To make the sliding surfaces of both cylinders as perfectly parallel as possible, the 
left specimen was rotated at an equivalent slip rate (see below for the definition) of $2.6 \mathrm{~mm} / \mathrm{s}$ under normal stresses $\left(\sigma_{\mathrm{n}}\right)$ of 1.0-3.0 $\mathrm{MPa}$. Then, wear materials were removed from the contact area. High-velocity friction experiments were conducted at room temperature and humidity conditions using a rotary shear, high-velocity frictional testing apparatus at Yamaguchi University. A detailed description of the apparatus is in Shimamoto and Tsutsumi (1994) and Hirose and Shimamoto (2005). Axial forces of 2.5-6.4 kN were applied to the pair of specimens using an air actuator. The rotation of the motor was transmitted to the specimen via an electromagnetic clutch. Axial load, torque, and axial displacement were measured using a force gauge, torque gauge, and axial transducer, respectively, at a sampling frequency of $200 \mathrm{~Hz}$. Experiments were conducted at normal stresses $\left(\sigma_{\mathrm{n}}\right)$ of 5,10 , and $13 \mathrm{MPa}$. To investigate the reproducibility of the frictional strength curves, we tested the friction experiments at the same $\sigma_{\mathrm{n}}$ expect for $\sigma_{\mathrm{n}}=13 \mathrm{MPa}$. In the case of solid cylindrical specimens, the slip rate linearly increases from 0 at the center to a maximum at the edge. We used an equivalent slip rate $\left(V_{\mathrm{e}}\right)$ as follows (Shimamoto and Tsutsumi 1994):

$$
V_{\mathrm{e}}=\frac{4}{3} \pi r R
$$

where $r$ and $R$ are the radius of the solid cylindrical specimen $(25 \mathrm{~mm})$ and the revolution rate of the motor $(1500 \mathrm{rpm})$, respectively. Hereafter, we refer to $V_{\mathrm{e}}$ as the slip rate. Assuming constant shear stress $(\tau)$ over the sliding surface area, the shear stress $(\tau)$ was converted from the measured torque $(T)$ as follows:

$$
T=\tau \int_{0}^{r} 2 \pi r^{2} \mathrm{~d} r
$$

where $T$ is the torque and $r$ is the radius of the cylindrical specimen. The apparent friction coefficient $(\mu)$ was defined as $\tau / \sigma_{\mathrm{n}}$. The experiments were monitored using a digital video camera.

After the experiments, the sample assembly was impregnated with a low-viscosity epoxy resin and then cut through the axis of the cylinder to create a radial section for microstructural observation and chemical analysis. The chemical composition of the pseudotachylyte matrix was analyzed using an electron probe microanalyzer (JXA-8530F) with an accelerating voltage of $15 \mathrm{kV}$ and a current of $1.1 \mathrm{nA}$. We used a focused beam $\sim 1 \mu \mathrm{m}$ in diameter to analyze only the matrix and adopted an average of 10-20 points per pseudotachylyte as a representative chemical composition.

\section{Results}

\section{Frictional behavior of chert at seismic slip rates}

Figure 1a shows a representative experimental result at a $\sigma_{\mathrm{n}}$ of $5 \mathrm{MPa}$. At the beginning of sliding, $\mu$ reached a peak value of 0.4 then decreased to 0.3 . This initial weakening was followed by slip strengthening toward a second peak value of 0.8. Subsequently, a second slip weakening occurred toward a steady-state $\mu$ value of $\sim 0.5$. The digital video camera data indicate that reddish melt patches evolved to a yellow continuous melt layer during slip strengthening (Fig. 1c, d). The melt squeezing was recognized after the formation of a melt layer (Fig. 1d, e), which is also reflected by the increased axial shortening (Fig. 1a). Figure 2 shows the experimental results at $\sigma_{\mathrm{n}}$ of $5-13 \mathrm{MPa}$. There is a dependence of $\tau$ on $\sigma_{\mathrm{n}}$ during the initial slip weakening and early stage of slip strengthening.

\section{Microstructures and chemical composition}

The resultant microstructures were examined under an optical microscope and field-emission scanning electron microscope (JEOL JSM-IT300HR). The microstructures indicated that the melt patches developed during slip strengthening (Fig. 3a, b).The experimentally generated pseudotachylyte is composed of a grayishwhite matrix with quartz fragments under plane-polarized light. The boundaries of the pseudotachylyte are locally rounded and embayed (Fig. 3c). The pseudotachylyte matrix is optically isotropic under cross-polarized light (Fig. 3d). The chert $0.4-0.8 \mathrm{~mm}$ from the pseudotachylyte boundary is dark under plane-polarized light and optically isotropic under cross-polarized light (Ac in Fig. 3c, d). Quartz veins in the chert are cut by the pseudotachylyte layer, but altered chert preserves these quartz veins.

Under back-scattered electron (BSE) images, the pseudotachylyte matrix is brighter than the host rocks and fragments (Fig. 3e-g). Some quartz grains exhibit embayed and rounded margins (Fig. 3f). In places, cracks develop along the margin of the quartz fragment (Fig. 3g), possibly representing differential cooling between the glassy matrix and fragment (Spray 1993). The matrix of altered chert is brighter than the quartz (Fig. 3h). Tiny vesicles $0.1-0.8 \mu \mathrm{m}$ in diameter occur in the matrix of the altered chert (Fig. 3i). Energy-dispersive X-ray spectrometry (EDS) detected peaks for $\mathrm{Si}, \mathrm{Al}, \mathrm{Mg}, \mathrm{K}$, and Fe from the matrix of the altered chert (Fig. 3j). The results of the chemical composition are shown in Table 1 . The pseudotachylyte matrix has high Si content with a lesser amount of $\mathrm{K}$, $\mathrm{Al}, \mathrm{Mg}$, and Fe. 

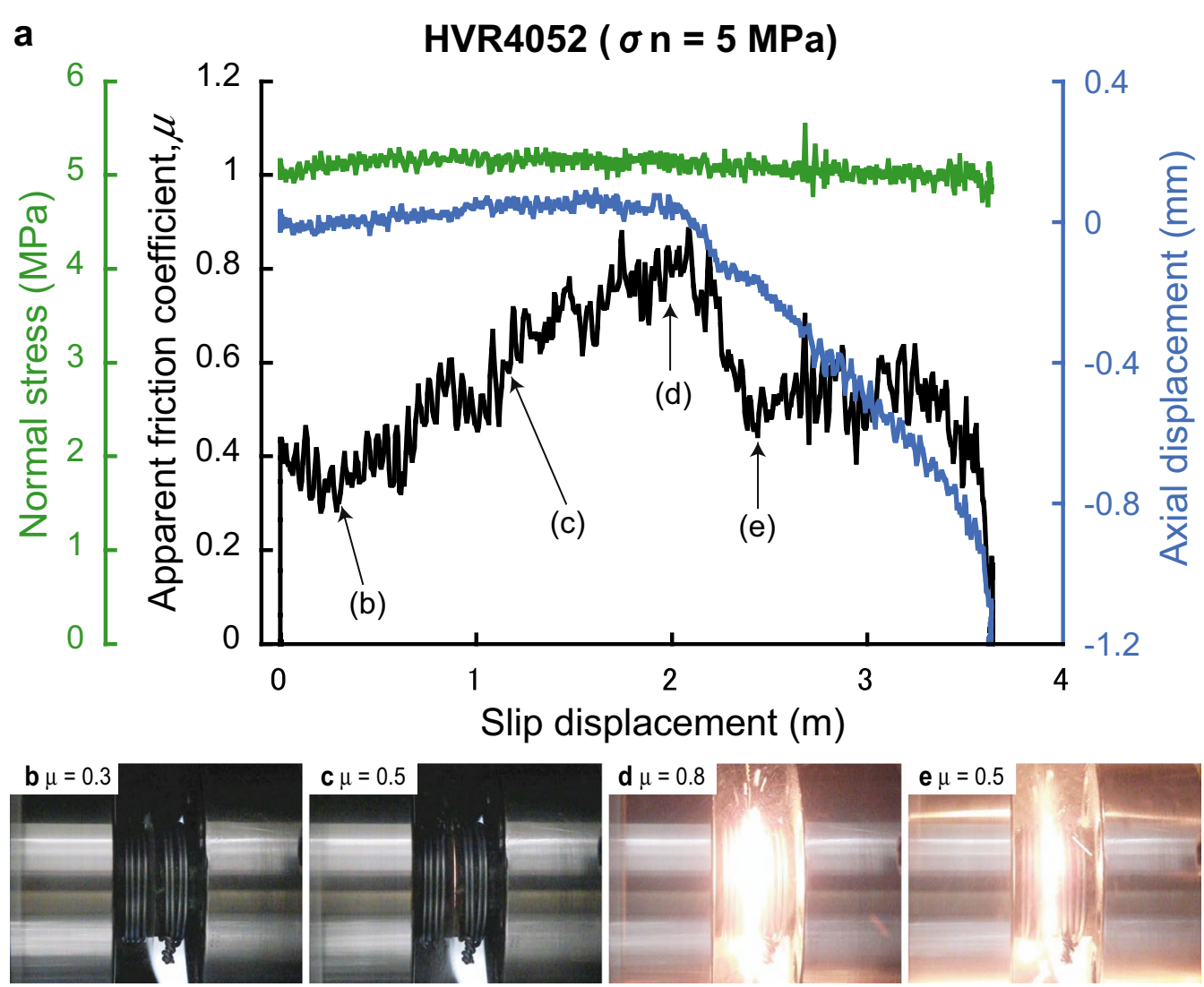

Fig. 1 Representative high-velocity frictional behavior of chert. a Experimental results showing the friction coefficient (black), axial displacement (blue), and normal stress (green) versus slip displacement. b-e Images captured using the digital video camera. Locations are shown in (a). b Wear materials are extruded after the initial slip weakening. $\mathbf{c}$ Reddish melt patches developed during slip strengthening. $\mathbf{d}$ Melt layer growth before second slip weakening. e Melt squeezing following the second slip weakening

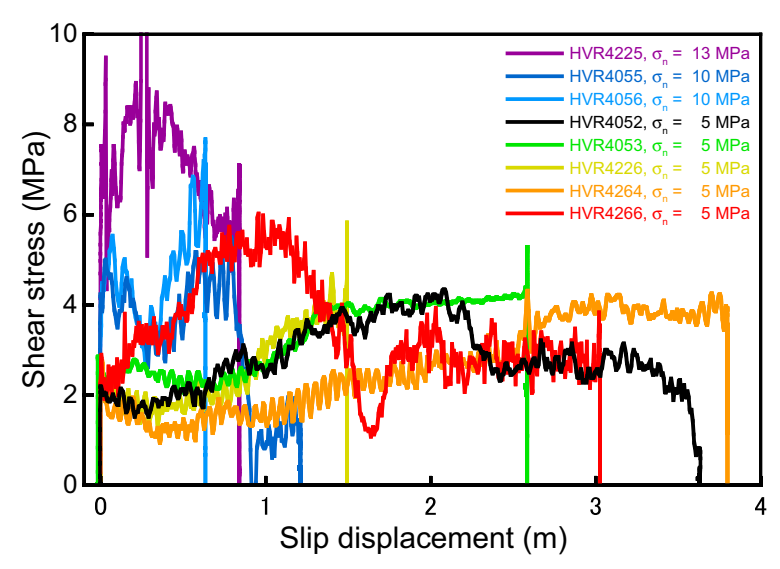

Fig. 2 Slip behavior of chert under three different normal stresses $\left(\sigma_{n}\right)$

\section{Discussion}

Microstructures and chemical compositions in and around pseudotachylytes

The chemical composition of the pseudotachylyte matrix suggests the melting of quartz with a small amount of illite. This is consistent with the gray chert mainly composed of microcrystalline quartz and radiolarians with a lesser amount of illite. The melting temperature of quartz is $1730{ }^{\circ} \mathrm{C}$ (Spray 1992) but may decrease to $1680{ }^{\circ} \mathrm{C}$ at a $\sigma_{\mathrm{n}}$ of $5 \mathrm{MPa}$ in the presence of water (Kennedy et al. 1962). Heating experiments on illite showed that it melted at a temperature higher than $1100{ }^{\circ} \mathrm{C}$ (Grim and Bradley 1940; McConville and Lee 2005). In addition, pseudotachylytes derived from illite-rich slipping zones record frictional melting at temperatures higher than $1100{ }^{\circ} \mathrm{C}$ (Ujiie et al. 2007; Ujiie and Kimura 2014). Thus, 


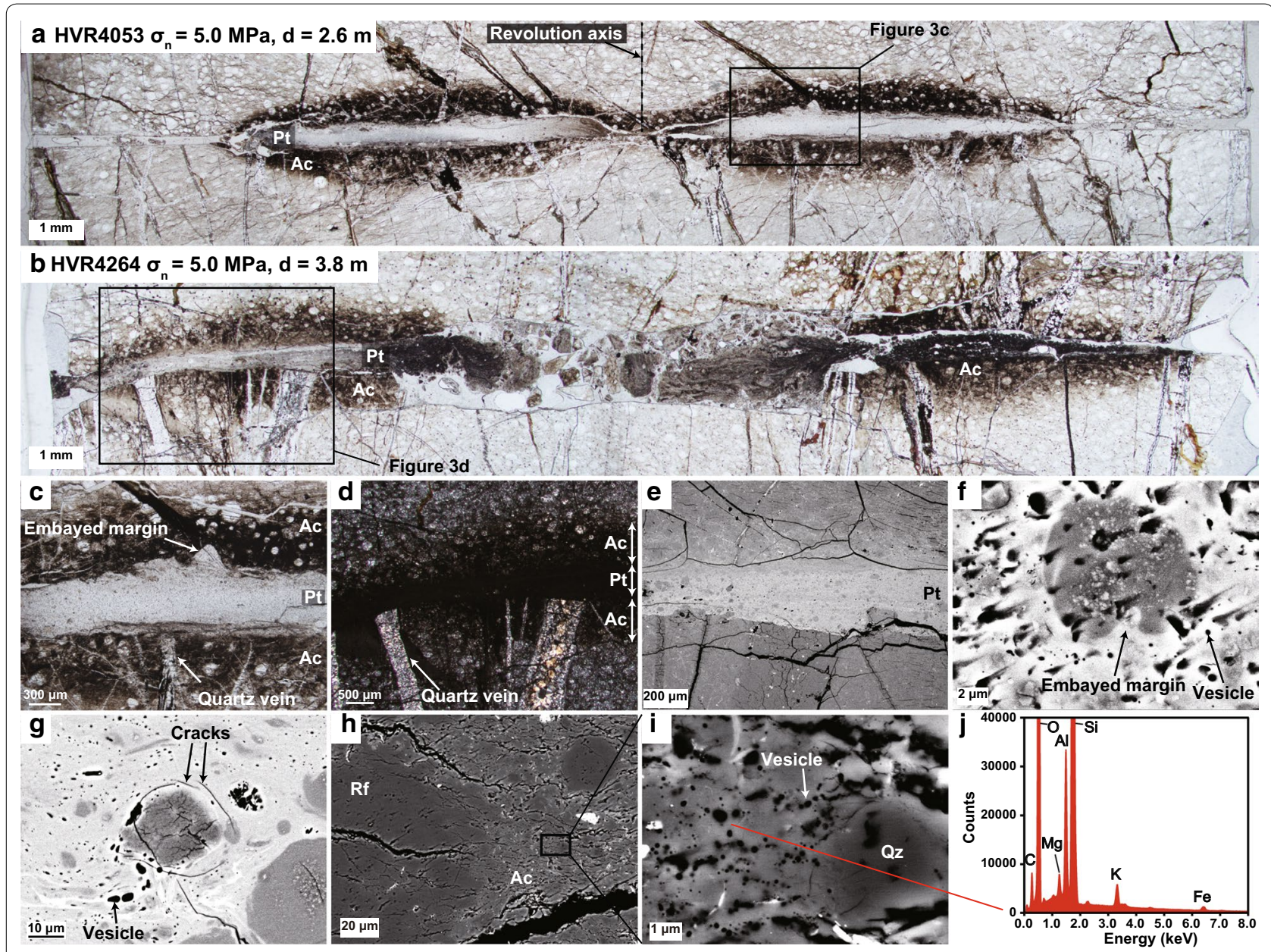

Fig. 3 Resultant microstructures. a-c Under plane-polarized light. a A pair of patchy pseudotachylytes (Pt) developed during slip strengthening. Note that the pseudotachylytes are mantled by the altered chert (Ac). b Pseudotachylyte (Pt) and altered chert (Ac) formed during the late stage of slip strengthening. c Pseudotachylyte boundary showing an embayed margin. Location of the figure is shown in (a). d Optically isotropic matrices of pseudotachylyte (Pt) and altered chert (Ac) under cross-polarized light. Note that the quartz veins are cut by pseudotachylyte but preserved in the altered chert (Ac). Location of the figure is shown in (b). e-i Under back-scattered electron (BSE) images. e Appearance of experimentally generated pseudotachylyte showing a fragment-laden, glass-supported texture. $\mathbf{f}$ A fragment in the pseudotachylyte matrix showing an embayed margin. $\mathbf{g}$ Cracks surrounding a fragment in the pseudotachylyte matrix. $\mathbf{h}$ A radiolarian fossil (Rf) in the matrix of the altered chert (Ac). $\mathbf{i}$ The presence of vesicles in the matrix of the altered chert. Location of the figure is shown in (h). Qz, quartz. j Energy-dispersive X-ray spectroscopy (EDS) spectrum of the matrix of the altered chert. Location of the measured point is shown in (i)

frictional melting of chert is considered to occur at least $1100{ }^{\circ} \mathrm{C}$.

The optically isotropic matrix with an illite composition under cross-polarized light and the presence of vesicles in the matrix of the altered chert suggest illite thermal decomposition and dehydration (Fig. 3d, i, j). Similar features were reported along the margins of experimentally generated pseudotachylyte derived from frictional melting of argillite (Ujiie et al. 2009). Experimental investigations of the thermal transformation of illite showed that its structure is disrupted at $700-850^{\circ} \mathrm{C}$ (Grim and Bradley 1940). The preservation of quartz veins in the altered chert demonstrates that it did not suffer from shear deformation (Fig. 3c, d). Therefore, chert is considered to be altered via heat diffusion from the molten zone at temperatures higher than $700-850^{\circ} \mathrm{C}$.

\section{Frictional behavior and underlying physical mechanisms during frictional melting of chert}

Frictional melting did not occur during initial slip weakening. This could represent flash heating at asperity contacts (Rice 2006; Goldsby and Tullis 2011). Axial shortening associated with melt squeezing and images captured by the digital video camera show that the melt 
Table 1 Experimental conditions, average chemical composition of pseudotachylyte matrix, grain volume fraction $\varphi$, and grain aspect ratio $r$

\begin{tabular}{lllll}
\hline Run & HVR4226 & HVR4264 & HVR4052 & HVR4266 \\
\hline$\sigma_{\mathrm{n}}[\mathrm{MPa}]$ & 5.0 & 5.0 & 5.0 & 5.0 \\
Displacement $[\mathrm{m}]$ & 1.5 & 3.8 & 3.6 & 3.0 \\
$\mathrm{SiO}_{2}$ & $92.9 \pm 0.5$ & $91.3 \pm 0.7$ & $92.8 \pm 1.1$ & $86.9 \pm 0.9$ \\
$\mathrm{TiO}_{2}$ & $0.2 \pm 0.04$ & $0.2 \pm 0.05$ & $0.2 \pm 0.05$ & $0.4 \pm 0.04$ \\
$\mathrm{Al}_{2} \mathrm{O}_{3}$ & $3.2 \pm 0.2$ & $3.5 \pm 0.1$ & $3.4 \pm 0.4$ & $6.6 \pm 0.4$ \\
$\mathrm{FeO}_{\mathrm{MnO}}$ & $1.1 \pm 0.1$ & $2.6 \pm 0.2$ & $1.1 \pm 0.2$ & $2.1 \pm 0.2$ \\
$\mathrm{MgO}$ & - & - & - & - \\
$\mathrm{CaO}$ & $0.6 \pm 0.1$ & $1 \pm 0.1$ & $0.6 \pm 0.1$ & $1.1 \pm 0.1$ \\
$\mathrm{Na}$ & $\mathrm{O}$ & $0.1 \pm 0.01$ & - & $0.1 \pm 0.01$ \\
$\mathrm{~K}_{2} \mathrm{O}$ & - & - & - & $0.1 \pm 0.01$ \\
$\mathrm{Total}$ & - & $0.6 \pm 0$ & $0.9 \pm 0.1$ & $1.8 \pm 0.1$ \\
$\varphi$ & $0.9 \pm 0.1$ & 99.4 & 99.1 & 99.1 \\
$r$ & 99.0 & 0.09 & 0.08 & 0.13 \\
\hline
\end{tabular}

patches evolved to a continuous melt layer during slip strengthening (Fig. 1). During the initial slip weakening and early stage of slip strengthening, $\tau$ is higher for higher $\sigma_{\mathrm{n}}$ (Fig. 2). Although melt patches initiated during the early stage of slip strengthening, a dependence of $\tau$ on $\sigma_{\mathrm{n}}$ implies that the frictional behavior was maintained. Previous experiments on gabbro showed that melt patches were caused by selective melting of minerals with a low melting temperature (Tsutsumi and Shimamoto 1997; Hirose and Shimamoto 2005). Such preferential melting is unlikely to occur during frictional melting of chert because melt patches developed along chert that was mainly composed of microcrystalline quartz and radiolarians. The melt patches symmetrically developed with respect to the revolution axis (Fig. 3a). This suggests that their spatial distribution reflects the temperature distribution in the slipping zone, which was controlled by the rotation velocity at a distance away from the revolution axis.

A continuous melt layer formed during the late stage of slip strengthening (Fig. 1). The melt escape from the molten layer could be comparable to the melt injection from the melt generation zone in nature, although the former is more easy to occur than the latter because of smaller confining pressure during friction experiments. Assuming the Newtonian behavior of the melt layer, the viscous shear stress $\tau$ can be expressed as follows:

$$
\tau=\eta \frac{\mathrm{d} \gamma}{\mathrm{d} t}=\eta \frac{V_{\mathrm{e}}}{w}
$$

where $\eta$ is the apparent viscosity of the melt layer, $\mathrm{d} \gamma / \mathrm{d} t$ is the shear strain rate, $V_{\mathrm{e}}$ is the equivalent slip rate, and

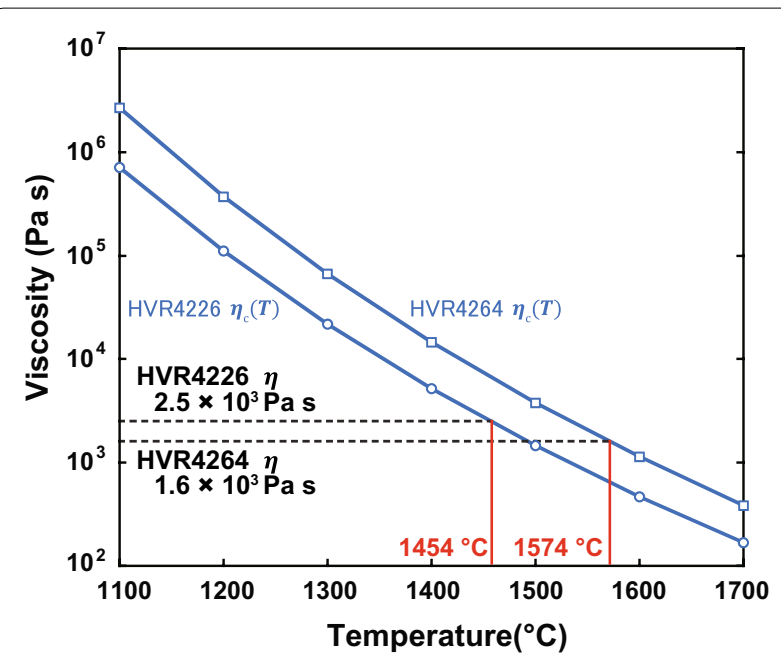

Fig. 4 Temperature dependence of the viscosity $\left(\eta_{c}\right)$ of the melt layer during slip strengthening at $\sigma_{n}$ of $5 \mathrm{MPa}$. $\eta$ denotes the viscosity determined from the experimental data and pseudotachylyte thickness. See text for further explanation

$w$ is the thickness of the melt layer. $\eta$ is determined by dividing the measured shear stress by the shear strain rate, which ranges from $(1.6-2.5) \times 10^{3} \mathrm{~Pa}$ s. Assuming the Arrhenian temperature dependence of the melt viscosity, the matrix viscosity of the melt layer $\left(\eta_{\mathrm{m}}\right)$ during slip strengthening can be calculated using the Shaw (1972) model as follows:

$$
\eta_{\mathrm{m}}(T)=A \exp \left(\frac{B}{T}\right)
$$

where $T$ is the absolute temperature, $A$ is the reference viscosity, and $B$ is the activation temperature (Spray 1993; Fialko and Khazan 2005; Ujiie et al. 2007). As pseudotachylytes contain solid fragments, the matrix viscosity was corrected to obtain the viscosity of the melt layer $\left(\eta_{c}\right)$ using the following empirical equation (Kitano et al. 1981):

$$
\eta_{c}(T)=\eta_{\mathrm{m}}(T) \times\left[1-\left(\frac{\Phi}{A}\right)\right]^{-2}
$$

with $A=0.54-0.0125 r$, where $\phi$ is the volume fraction of the solid grains, $A$ is the parameter related to the packing geometry of the solid grains, and $r$ is the average aspect ratio of the solid grains. We measured $\phi$ in the pseudotachylyte layer using BSE images with a 1500 -fold magnification. Figure 4 indicates the relationship between $\eta_{c}$ and temperature. The $\eta$ values determined from the experimental data and the pseudotachylyte layer thickness are compatible with the $\eta_{c}$ values when temperatures were $1454-1574{ }^{\circ} \mathrm{C}$. These values are considerably lower 
than the melting temperature of dry quartz $\left(1730{ }^{\circ} \mathrm{C}\right)$ (Spray 1992).

Friction experiments on gabbro have suggested that the welding of melt patches causes slip strengthening (Tsutsumi and Shimamoto 1997). However, friction experiments on sedimentary rocks (e.g., argillite and siltstone) showed that a continuous melt layer formed during slip strengthening, representing an increase in the viscosity associated with melt layer dehydration (Ujiie et al. 2009; Kuo et al. 2015). The chert-derived pseudotachylyte matrix is more silica-rich $(87-93 \%)$ than the pseudotachylyte matrices derived from argillite (60-63\%), siltstone (65-66\%), and gabbro (49-56\%) (Hirose and Shimamoto 2005; Ujiie et al. 2009; Kuo et al. 2015). Thus, the matrix viscosities of the chert-derived melt layer are high, $(1.6-2.5) \times 10^{3} \mathrm{~Pa}$ s at $1454-1574{ }^{\circ} \mathrm{C}$, compared to those of other rocks. Therefore, slip strengthening during melt layer development was caused by the formation of a viscous silica-rich melt layer at temperatures lower than expected (below $1730^{\circ} \mathrm{C}$ ).

The lower melting temperatures could have been a result of the presence of water in the chert. The presence of vesicles in the pseudotachylyte is consistent with the formation of a hydrous melt layer (Fig. 3f, g). The melting temperature of quartz decreases in the presence of water; it is reduced to $1680{ }^{\circ} \mathrm{C}$ at a $\sigma_{\mathrm{n}}$ of $5 \mathrm{MPa}$ (Kennedy et al. 1962). Because fluid inclusions are not observed in the chert, the water may have been derived from the grain boundary of the microcrystalline quartz, radiolarians, and chemically bound water $(\mathrm{OH})^{-}$with some absorbed and interlayer water in the illite. Previous experimental study shows that the addition of $1.0 \mathrm{wt} \%$ of $\mathrm{K}_{2} \mathrm{O}$ and $6.5 \mathrm{wt} \%$ of $\mathrm{Al}_{2} \mathrm{O}_{3}$ to $\mathrm{SiO}_{2}$ reduces the melting temperature from $1713{ }^{\circ} \mathrm{C}$ to $1555^{\circ} \mathrm{C}$ (Schairer and Bowen 1955). Because the chemical composition of the pseudotachylytes includes $0.6-0.9 \mathrm{wt} \%$ of $\mathrm{K}_{2} \mathrm{O}$ and $3.2-3.5 \mathrm{wt} \%$ of $\mathrm{Al}_{2} \mathrm{O}_{3}$ due to the melting of illite, the formation of alkali silicate melts may have also decreased the melting temperature. Recently, Lee et al. (2017) reported that amorphous silica nanoparticles $10-20 \mathrm{~nm}$ in diameter melted at $\sim 1600{ }^{\circ} \mathrm{C}$. Although the chert samples were mainly composed of microcrystalline quartz $20 \mu \mathrm{m}$ or less in diameter, comminution due to frictional sliding might have produced amorphous silica nanoparticles, resulting in a lower melting temperature. Another possibility is the metastable melting of $\beta$-quartz at $\sim 1400{ }^{\circ} \mathrm{C}$ (Bourova and Richet 1998). In fact, Lee et al. (2017) found $\beta$-quartz in experimentally generated pseudotachylyte derived from the frictional melting of quartzite, which could reduce the melting temperatures to $1350-1500^{\circ} \mathrm{C}$. A similar feature may also occur during the frictional melting of chert.

The chemical composition of the pseudotachylyte matrix is very similar before and after the second slip weakening (see HVR 4226 and HVR4052 in Table 1). In addition, the volume fraction of the solid grains $(\phi)$ remained almost constant before and after the second slip weakening. This suggests that melt viscosity may not be changed in response to changes in chemical composition and $\phi$ in the melt layer. Instead, the second slip weakening may be caused by a decreased shear strain rate associated with an increase in melt layer thickness (Hirose and Shimamoto 2005).

\section{Conclusion}

We examined the high-velocity frictional properties of pelagic chert and the underlying physical mechanisms. Our results indicate that the initial slip weakening followed by slip strengthening and subsequent second slip weakening toward a steady state. The slip strengthening was caused by the formation of a viscous silica-rich melt layer at temperatures of $1454-1574{ }^{\circ} \mathrm{C}$, well below the melting temperature of dry quartz at $1730{ }^{\circ} \mathrm{C}$. The lower melting temperature could be attributed to the presence of water in the illite-containing chert. A second slip weakening occurred due to a decrease in the shear strain rate associated with the increase in melt layer thickness.

\section{Additional file}

Additional file 1. (a) Photomicrograph of the host rock adjacent to the pseudotachylyte under cross-polarized light. Qz: quartz, Il: illite. (b) The same as (a) with illite highlighted in orange color. The area fraction of illite is 0.01 .

\section{Abbreviations}

Ac: the altered chert; BSE: back-scattered electron; EDS: energy-dispersive X-ray spectroscopy; II: illite; Pt: pseudotachylytes; Qz: quartz; Rf: radiolarian fossil.

\section{Acknowledgements}

We would like to thank Akito Tsutsumi for assistance in using a coring machine at Kyoto University. We also thank Atsushi Kyono and Naoki Nishiyama for useful discussion and suggestions. Noah Phillips read the early version of the manuscript and provided thoughtful comments and suggestions. We are grateful for the thoughtful and helpful comments by the two anonymous reviewers and for the EPS Editor, Ryosuke Ando for the evaluation.

\section{Authors' contributions}

GM and KU wrote the manuscript. GM prepared the figures. GM, KO, and $\mathrm{KU}$ conducted the high-velocity friction experiments. GM and KU analyzed the experimental data and calculated viscosity. GM performed microstructural observation and chemical analyses. All authors read and approved the final manuscript

\section{Funding}

Kohtaro Ujiie is supported by the Grant-in-Aid for Scientific Research (B) from JSPS (26287124) and the Japan Society for the Promotion of Science KAKENHI Grant JP16H06476.

\section{Availability of data and materials}

The data that support the findings in the present study are available from the corresponding author upon a request. 
Ethics approval and consent to participate

Not applicable.

\section{Consent for publication}

Not applicable.

\section{Competing interests}

The authors declare that they have no competing interests.

\section{Author details}

${ }^{1}$ Graduate School of Life and Environmental Sciences, University of Tsukuba, 1-1-1 Tennodai, Tsukuba 305-8572, Japan. ${ }^{2}$ Graduate School of Sciences and Technology for Innovation, Yamaguchi University, 1677-1 Yoshida, Yamaguchi 753-8512, Japan.

Received: 7 February 2019 Accepted: 10 May 2019

Published online: 22 May 2019

\section{References}

Bestmann M, Pennacchioni G, Frank G, Göken M, de Wall H (2011) Pseudotachylyte in muscovite-bearing quartzite: coseismic friction-induced melting and plastic deformation of quartz. J Struct Geol 33:169-186. https://doi. org/10.1016/j.jsg.2010.10.009

Bourova E, Richet P (1998) Quartz and cristobalite: high-temperature cell parameters and volumes of fusion. Geophys Res Lett 25:2333-2336. https ://doi.org/10.1029/98GL01581

Di Toro G, Goldsby DL, Tullis TE (2004) Friction falls towards zero in quartz rock as slip velocity approaches seismic rates. Nature 427:436-439. https://doi. org/10.1038/nature02249

Fialko Y, Khazan Y (2005) Fusion by earthquake fault friction: stick or slip? J Geophys Res Solid Earth 110:1-15. https://doi.org/10.1029/2005JB003869

Goldsby DL, Tullis TE (2002) Low frictional strength of quartz rocks at subseismic slip rates. Geophys Res Lett 29:1844. https://doi.org/10.1029/2002G L015240

Goldsby DL, Tullis TE (2011) Flash heating leads to low frictional earthquake slip rates. Science 334:216-218. https://doi.org/10.1126/science.1207902

Grim RE, Bradley WF (1940) Investigation of the effect of heat on the clay minerals illite and montmorillonite. J Am Ceram Soc 23:242-248. https:// doi.org/10.1111/j.1151-2916.1940.tb14263.x

Hayashi N, Tsutsumi A (2010) Deformation textures and mechanical behavior of a hydrated amorphous silica formed along an experimentally produced fault in chert. Geophys Res Lett 37:1-5. https://doi. org/10.1029/2010GL042943

Hirose T, Shimamoto T (2005) Growth of molten zone as a mechanism of slip weakening of simulated faults in gabbro during frictional melting. J Geophys Res Solid Earth 110:B05202. https://doi.org/10.1029/2004JB003207

Kennedy GC, Wasserburg GJ, Heard HC, Newton RC (1962) The upper threephase region in the system $\mathrm{SiO}_{2}-\mathrm{H}_{2} \mathrm{O}$. Am J Sci 260:501-521. https://doi. org/10.2475/ajs.260.7.501

Kirkpatrick JD, Rowe CD, White JC, Brodsky EE (2013) Silica gel formation during fault slip: evidence from the rock record. Geology 41:1015-1018. https://doi.org/10.1130/G34483.1
Kitano T, Kataoka T, Shirota T (1981) An empirical equation of the relative viscosity of polymer melts filled with various inorganic fillers. Rheol Acta 20:207-209. https://doi.org/10.1007/BF01513064

Kuo LW, Song YF, Yang CM, Song SR, Wang CC, Dong JJ, Suppe J, Shimamoto T (2015) Ultrafine spherical quartz formation during seismic fault slip: natural and experimental evidence and its implications. Tectonophysics 664:98-108. https://doi.org/10.1016/j.tecto.2015.09.008

Lee SK, Han R, Kim EJ, Jeong GY, Khim H, Hirose T (2017) Quasi-equilibrium melting of quartzite upon extreme friction. Nat Geosci 10:436-441. https ://doi.org/10.1038/ngeo2951

McConville CJ, Lee WE (2005) Microstructural development on firing illite and smectite clays compared with that in kaolinite. J Am Ceram Soc 88:2267-2276. https://doi.org/10.1111/j.1551-2916.2005.00390.x

Ohtomo Y, Shimamoto T (1994) Significance of thermal fracturing in the generation of fault gouge during rapid fault motion: an experimental verification. Struct Geol 39:135-144 (in Japanese with English abstract)

Rice JR (2006) Heating and weakening of faults during earthquake slip. J Geophys Res Solid Earth 111:B05311. https://doi.org/10.1029/2005JB004006

Schairer JF, Bowen NL (1955) The system $\mathrm{K}_{2} \mathrm{O}-\mathrm{Al}_{2} \mathrm{O}_{3}-\mathrm{SiO}_{2}$. Am J Sci 253:681746. https://doi.org/10.2475/ajs.253.12.681

Shaw HR (1972) Viscosities of magmatic silicate liquids; an empirical method of prediction. Am J Sci 272:870-893. https://doi.org/10.2475/ajs.272.9.870

Shimamoto T, Tsutsumi A (1994) A new rotary-shear high-speed frictional testing machine: its basic design and scope of research. Struct Geol 39:65-78 (in Japanese with English abstract)

Spray JG (1992) A physical basis for the frictional melting of some rock-forming minerals. Tectonophysics 204:205-221. https://doi.org/10.1016/00401951(92)90308-S

Spray JG (1993) Viscosity determinations of some frictionally generated silicate melts: implications for fault zone rheology at high strain rates. J Geophys Res 98:8053-8068. https://doi.org/10.1029/93JB00020

Tsutsumi A, Shimamoto T (1997) High-velocity frictional properties of gabbro. Geophys Res Lett 24:699-702. https://doi.org/10.1029/97GL00503

Ujiie K, Kimura G (2014) Earthquake faulting in subduction zones: insights from fault rocks in accretionary prisms. Prog Earth Planet Sci 1:7. https://doi. org/10.1186/2197-4284-1-7

Ujiie K, Yamaguchi H, Sakaguchi A, Toh S (2007) Pseudotachylytes in an ancient accretionary complex and implications for melt lubrication during subduction zone earthquakes. J Struct Geol 29:599-613. https://doi. org/10.1016/j.jsg.2006.10.012

Ujiie K, Tsutsumi A, Fialko Y, Yamaguchi H (2009) Experimental investigation of frictional melting of argillite at high slip rates: implications for seismic slip in subduction-accretion complexes. J Geophys Res Solid Earth 114:B04308. https://doi.org/10.1029/2008JB006165

\section{Publisher's Note}

Springer Nature remains neutral with regard to jurisdictional claims in published maps and institutional affiliations.

\section{Submit your manuscript to a SpringerOpen ${ }^{\circ}$ journal and benefit from:}

- Convenient online submission

- Rigorous peer review

- Open access: articles freely available online

- High visibility within the field

Retaining the copyright to your article

Submit your next manuscript at springeropen.com 